\title{
Cross-cultural impact of work-life balance on health and work outcomes
}

\author{
Carolyn Timms, Paula Brough, Oi-Ling Siu, Michael O'Driscoll, and Thomas Kalliath
}

\begin{abstract}
In this chapter we describe some of our recent work-life balance research conducted between regional groups within the Asia-Pacific area. The research component of this chapter explores the applicability, testing and extension of theories of organisational behaviour from Western to non-Western contexts. More specifically, we explore the relevance of the work-life balance construct to workers and societies who may have different competing priorities. In this chapter we first discuss the numerous definitions and measures of the work-life balance construct. We present data from some of our recent research testing a new measure of worklife balance amongst 11,421 workers sampled from China, Hong Kong, New Zealand and Australia. We then discuss the rise of industry and rapid social change in China which may influence interpretations of work behaviour. Finally, we return to a more general examination of key issues in regard to modern technology and its potential for encroachment on work-life boundaries. In particular we examine the emerging cross-cultural research in this area.
\end{abstract}

\section{IDENTIFYING A DEFINITION OF WORK-LIFE BALANCE}

Multiple work-life balance definitions exist and have been recently discussed by scholars in this field. Work-life balance can be defined by the type of demands elicited by work and non-work environments such as strain-based, behaviour-based and time-based demands (Greenhaus \& Beutell, 1985) and by the specific methods by which work and nonwork roles interact with one another, such as spillover, compensation, conflict and interference (Carlson, Kacmar, \& Williams, 2000). Explanations of how work-life balance interacts with individual health and performance outcomes are drawn from multiple theoretical perspectives including models based on role theory (Greenhaus \& Beutell, 1985) cognitive appraisal (Edwards \& Rothbard, 1999), role salience (Noor, 2004), and job demands-resources (Voydanoff, 2005). Recent refinements to the theoretical explanations of work-life balance focus on the inclusion of positive as well as negative relationships between domains, largely via the recognition that both work demands and non-work demands may 
facilitate, enrich, and/or enhance health and performance outcomes (Brough et al., 2014). Evidence is generally consistent in identifying work and family demands and responsibilities for dependents as key antecedents of work-life balance; gender and social support as key moderating constructs; and satisfaction, performance and levels of both physical and psychological health as the core consequences of work-life balance (Brough et al., 2014).

Kalliath and Brough's (2008) definition of work-life balance as: "the individual's perception that work and non-work activities are compatible and promote growth in accordance with an individual's current life priorities” (p. 326) suggests several important discussion issues. Firstly, work-life balance is portrayed as a subjective entity, best assessed by the individual themselves, rather than something which can be objectively calculated by their employer or spouse. Secondly, this definition of work-life balance does not specify that the time spent in work and non-work life domains has to be equivalent in length, as some previous research has noted. For example, Kalliath and Brough suggested it is feasible that part-time workers can have a sense of work-life balance even though such employees spend more time in their non-work domain than in their paid employment.

Kalliath and Brough's (2008) definition of work-life balance instead emphasises the individual's subjective assessment of a balance or compatibility between their multiple life roles. Therefore, the construct of work-life balance incorporates personal and subjective comfort in relation to the concurrence of work and non-work spheres. Thirdly, a sense of work-life balance involves positive growth, learning, and employee engagement (see also, Richman, Civian, Shannon, Hill, \& Brennan, 2008). Finally, Kalliath and Brough acknowledged the essential issue of role salience in work-life balance. Thus the arrival of a new baby may mean an employee temporarily places more importance and energy upon their home life, compared to their paid employment. While a new promotion at work may focus more effort and energy on paid employment. Thus an employee's role salience and their requirements from organisational work-life balance policies obviously change in direct response to important and/or critical life and work events. Kalliath and Brough (2008), therefore, suggested that the assessment of work-life balance should include question items seeking individual's perceptions of 'balance', primary because the term 'work-life balance' has an increased validity for research participants in comparison to other terms such as ‘conflict', ‘interference', or 'facilitation'. 
Brough et al.'s (2014) new measure of work-life balance was based on the insights provided in Kalliath and Brough's (2008) definition. Brough et al. (2014) therefore, described the essential characteristics of work-life balance as successful navigation by employees of their joint commitments to their work and non-work roles. This is predicated on their own perceptions of role salience, irrespective of the proportions of time and involvement physically spent in these roles. Brough et al.'s (2014) work-life balance measure consists of four items asking respondents directly about their perceptions of work-life balance. Importantly, Brough et al. (2014) adopted a cross-national approach for the development and validation of this measure; the measure was tested in samples of workers from New Zealand, Australia, Hong Kong and China. However, only the empirical results for the New Zealand and Australian samples were published in Brough et al. For the purposes of demonstrating cross-national equivalence of the work-life balance construct, we briefly describe the Hong Kong and China results here.

\section{Research Sample}

Brough et al. (2014) described the four independent New Zealand and Australian samples $(\mathrm{N}=6,983)$ in detail. The measure was also administered to 3,871 Chinese workers and 567 Hong Kong employees. All the research participants were recruited from a heterogeneous sample of industries which included: public service, high technology organizations, retail, media, health, education, finance, manufacturing, and non-government organizations. Questionnaires administered to the Hong Kong and Chinese participants were translated into Chinese and back translated into English to verify semantic equivalence. The Hong Kong and Chinese researchers verified the accuracy of these translations and that each translated construct maintained its meaning; a common method employed to confirm translation accuracy. The translated work-life balance measure was checked for reliability by test-retest procedures over a two week period and produced minimum coefficients of .79. In all regional areas questionnaires were posted in each organisation's internal mail system to the research participants and returned via reply-post directly to the researchers at their respective local institutions. Some questionnaires were also administered on-line, due to organisational preference. Response rates varied across the six samples ranging from $10 \%$ to $52 \%$, with an average response rate of 33\%. Responses were higher from those organizations who posted questionnaire packs to specific (named) employees. 


\section{Work-Life Balance Measure}

The four item measure of measure of work-life balance was described in detail by Brough et al. (2014). The four scale items are: (1) 'I currently have a good balance between the time I spend at work and the time I have available for non-work activities', (2) 'I have difficulty balancing my work and non-work activities' (negatively worded item), (3) 'I feel that the balance between my work demands and non-work activities is currently about right', and (4) 'Overall, I believe that my work and non-work life are balanced'. The respondents were asked to respond to the items by reflecting on their work and non-work activities (i.e., regular activities outside of work such as family, friends, sports and study) over the past few months. Respondents indicated their agreement on a five-point scale from 1 (strongly disagree) to 5 (strongly agree). High scores represent perceptions of high balance.

\section{Results: Structure of the Work-Life Balance Measure}

The four-item work-life balance measure was subjected to confirmatory factor analysis (CFA) in the six independent samples and was tested in multi-group and longitudinal structural equation models (SEMs) to assess its relationships with recognised antecedent and outcome variables (see Brough et al., 2014). Preparation of the data sets for SEM included the deletion of cases missing at least half of the item responses from each individual measure (Brough, O'Driscoll, \& Kalliath, 2005). Missing values analysis employing expectationmaximisation was conducted (in SPSS) on each data set, to facilitate the SEM analysis.

The CFA fit indices (Table 1) indicated the measure had a good fit overall. The internal reliability estimates (Cronbach's alpha) for the work-life balance measure for each sample were also acceptable, ranging from .75 to .94 (Table 1). Figure 1 illustrates that the four work-life balance items accounted for acceptable proportions of variance (square multiple correlations (R2) greater than .30). Figure 1 also illustrates that no residual correlations were specified between the four items, thereby confirming the unidimensionality of this measure.

\section{Results: Criterion Validity of the Work-Life Balance Measure}


This new measure of work-life balance was also tested for its associations with one recognised antecedent of work-life balance: work demands (Boyar, Carr, Mosley, \& Carson, 2007) and with four recognised outcomes of work life balance: job satisfaction (Seashore, Lawler, Mirvis, \& Cammann, 1982), family satisfaction (Edwards \& Rothbard, 1999), turnover intentions (Brough \& Frame, 2004), and psychological strain (Kalliath, O'Driscoll, \& Brough, 2004). Associations between work-life balance and the criterion variables were tested in both cross-sectional and longitudinal analyses. Only the longitudinal analyses in the Australia 1 and China samples are presented here for brevity; full details of these measures and analyses are described in Brough et al. (2014).

For the Australian sample, the work-life balance (Time 1) measure was significantly predictive of three of the four Time 2 criterion variables: job satisfaction, turnover intentions and psychological strain (Figure 2). These results were not, however, replicated in the Chinese data where these relationships were all non-significant. The goodness-of-fit statistics are presented in Table 2 and produced acceptable results for both samples.

\section{REVIEW OF THE WORK-LIFE BALANCE MEASURE}

The analyses validated the four-item measure of work-life balance in six independent samples from four countries $(\mathrm{N}=11,421)$. The unidimensional factor structure of this worklife balance measure was replicated in each sample, producing adequate and comparable fit statistics. This result is particularly noteworthy given the variations in the sample characteristics, such as predominantly female samples (China and Australia 2), a predominantly male sample (Australia 3) and a predominantly young sample (China). The work-life balance measure also demonstrated adequate levels of criterion-related validity in all samples. The four-item measure of work-life balance was therefore substantiated by the analyses, supporting this component of the work-life balance definition proposed by Kalliath and Brough (2008). However it was also observed that there were differences in regard to predictive validity of the measure. The longitudinal analyses found that the work-life balance measure predicted psychological strain, intentions to turnover and job satisfaction within the Australian sample but not the Chinese sample.

The observed relationships between work-life balance and the research variables replicated published observations offering further support to the validity of the work-life 
balance measure. For example, Lapierre et al. (2008) reported significant standardised coefficients ranging between -.13 to -.48 between measures of work/family interference and job/family satisfaction, which are comparable with our results. Spector et al. (2007) also reported significant associations of .16 to .22 between measures of work-family interference and turnover intentions in samples of Chinese and Australian respondents and significant associations of .24 to .34 between work-family interference and workload, which again are comparable with the results we report here. Finally, the associations between work-life balance and psychological strain for the Chinese sample in the present research also corroborate reported relationships in a Chinese investigation by Chen, Siu, Lu, Cooper, and Phillips (2009), who suggested that work-life balance may mediate the association between job stress and depression. Published examples of longitudinal work-life balance research are scarce, but estimations comparable with those reported here were cited by O’Driscoll, Brough, and Kalliath (2004). The relationships observed by the current research therefore, compare favourably with the reported associations between measures of work-life conflict/interference/balance and recognised correlates. These comparisons offer further support for the validity of this new work-life balance measure.

This research included data collected in four countries to compare responses to key work-life balance variables. Importantly, the responses to the new work-life balance measure (Brough al., 2014) were replicated across all of the samples. However, the longitudinal analyses produced significant differences between the Australian and Chinese samples, supporting recent observations of differences in the influence of the psychosocial work environment on outcomes for workers employed in Anglo and Asian countries (Brough, Dollard, \& Tuckey, 2014). Explanations for why these differences occurred are of interest for subsequent research and it is suggested are likely to be influenced by three specific circumstances briefly discussed here: respondent demographic characteristics, cultural differences, and/or labor market differences.

The Australian and Chinese respondents were found to differ on a number of demographic characteristics including age, marital status, education level, and dependents, which may have implications for the experience of work-life balance among these respondents. These two samples also differed in their reported mean scores on the research constructs, with levels of job satisfaction being notably higher for the Australian respondents. This finding may simply be attributed to the fact that older workers generally record higher 
levels of job satisfaction compared to their younger colleagues (Brough, O’Driscoll, Kalliath, Cooper, \& Poelmans, 2009). Alternatively, it may echo previous research findings in Asian contexts where cultural differences influence people's tendency to indicate middle rather than extreme responses on survey items (see, Harzing, Brown, Koster, \& Zhao, 2012). The variations in the results produced by the Australian and Chinese respondents may also have occurred due to a fundamental difference in attitudes about work (e.g., organisational commitment) and family, which has been previously identified. Both Brough et al. (2013) and Spector et al. (2007) reported similar differences between Asian and Anglo employees, and suggested that the recognition common to employees within individualistic cultures that employment should fulfill higher order needs concerning recognition, support and reward (i.e., job satisfaction) is perceived markedly differently among workers within collectivist cultures.

The sample differences found in our research could be influenced by one or all of these explanations. It is certainly pertinent for further research to deduce whether these differences are influenced by cultural norms such as higher levels of loyalty exhibited by Chinese/Asian employees, or by external factors such as more competitive labour markets, or by practical issues such as greater financial responsibilities for extended family members resulting in less worker mobility for Asian workers compared to their Anglo counterparts. These national differences have also been identified by some cross-cultural researchers (Morris, Podolny, \& Sullivan, 2008). Lu, Siu, and Lu (2010) for example, reported that affective commitment moderated work stressors-job satisfaction relationships in samples of Hong Kong and Chinese workers. Specifically, Lu et al. demonstrated that high levels of organisational loyalty buffered some of the noxious effects of stress on job satisfaction.

This empirical research presents a short and valid measure of work-life balance suitable for inclusion in subsequent research investigations. The unidimensional structure of the work-life balance measure was demonstrated in six large independent samples $(\mathrm{N}=$ 11,421). The criterion-related validity of the work-life balance measure was also demonstrated in two large independent samples from different countries. Work demands were found to be a significant antecedent of work-life balance, while job satisfaction, family satisfaction, psychological strain and turnover intentions were each significant outcomes of work-life balance within the Australian sample. The research therefore demonstrated that research items asking directly about 'work-life balance' had an acceptable level of face 
validity for the respondents. Overall, this research successfully introduces a concise measure with robust psychometric properties, suitable for inclusion in subsequent research. We have also demonstrated that differences exist in the pathways of influence between the research variables when comparing Australian and Chinese respondents. Job satisfaction in particular, is a variable demonstrating marked differences between these two samples of workers. We now discuss some key explanations for why such differences between Anglo and Asian workers may exist and we start with reviewing the rise of industry in China. It is noted that in referring to China we refer to Hong Kong where relevant. Hong Kong (a large commercial center formerly under British jurisdiction) was returned to China in 1997 and therefore has a different historical trajectory in regard to industrialization. While there are historical, commercial and lifestyle differences between China and Hong Kong, the dominant culture is Chinese (Hong, Morris, Chiu, Benet-Martinez, 2000).

\section{THE RISE OF INDUSTRY IN CHINA}

Since 1978 when China began a series of economic reforms, this large totalitarian and philosophically isolationist state has experienced a number of powerful economic transitions (Lin, 2012). There has been widespread internal migration, dramatic urbanisation with devastating environmental impacts and continuing social upheaval in response to increases in labour demands (Peng, 2011). China is now the world's second largest trading economy and foreign investment has been an important contributor to its rapid expansion and exponential productivity growth (Lin, 2012; Morrison, 2013). Foreign investors have rushed to establish their operations within China because of a ready availability of low cost labour (Zhang, Hannum, \& Wang, 2008). Because China is a late arrival on the manufacturing scene, it benefits from the previous experience of others thereby affording it the opportunity to streamline processes and avoid costly innovation and industrial upgrading (Lin, 2012).

However, short-term economic advantages may well be offset by longer-term societal and environmental impacts. Exponential industrialisation is superimposed on traditional societal conventions that are extremely ordered, Confucist, patriarchal and collectivist (Frenkel \& Peetz, 1998). Lu et al. (2010) advised that loyalty and commitment are central to Chinese collectivist values. Within traditional Chinese organisations it is customary for individual discomfort to be suppressed for the greater good of organisational interests. From a Western investor's perspective this could mean that organisations have a ready supply of 
compliant workers who shun disharmony. However, the obvious scope for an abuse of power on the part of employers is somewhat contained by an expectation of reciprocity inherent in the Chinese notion of loyalty (e.g., Lu et al., 2010) which is based on mutual understanding that each party will demonstrate respect for the other.

Therefore, on a philosophical level using the logic of Confucianism, management practices of hiring and firing which clearly violate this expectation of reciprocity could inevitably result in a dissatisfied workforce actively seeking more secure employment (Jiang, Baker, \& Frazier, 2009). In Western organisations, skilled workers with a psychological commitment to the company are sought after, as this is consistent with a competitive edge over rival companies (Clarke, Lee, \& Li, 2004; Frenkel, 2001; Hole, Zhong, \& Schwartz, 2010). In their discussion of Chinese workplace relations, Frenkel and Peetz (1998) warned that when skilled workers sensed they were being exploited, they would be just as likely to seek alternative employment as Western workers in the same situation. Several studies (e.g., Frenkel, 2001; Jiang et al., 2009; Liu, Siu, \& Shi, 2010) have demonstrated clear applications of the relationship between the psychosocial work environment and work-related mental health within Chinese organisations, which provides support for Frenkel and Peetz's reflection.

Employing organisations in China range from the most highly sought-after state-owned enterprises (SOEs, many of which have recently been privatised) to foreign-funded factories that employ for the most part under-educated rural migrant workers (Cooke, 2008). However previous exploitation of rural migrant workers does not extend to their more-educated children. Wang, Pan and Heerink (2013, p. 2) referred to these as "China's new generation of migrant workers”. Born under the one-child-per-family policy they prefer their urban lifestyle to the traditional rural one in which their parents were raised, are more aware of their rights and less deferential to authority than their parents' generation. Hence they are more likely to insist on formal contract arrangements for work, request on-the-job training, and refuse to perform dangerous or toxic work. As these workers are employed on the most basic blue collar level, this finding of Wang et al. suggests that conditions for retention of workers in China are in a state-of-flux. It may well be that the compliance observed by previous researchers (e.g., Frenkel, 2001; Frenkel \& Peetz, 1998; Zhang et al., 2008) is contingent on the reciprocity principle described by Lu et al. (2010) in a more cogent and meaningful way. 
Nevertheless, Xiao and Cooke (2012) observed that the current exponential growth for Chinese goods within the global marketplace has led to work intensification in most Chinese workplaces, with many workers working extremely long hours. Within Chinese work culture, conflict between work and life is regarded as a personal problem and addressing its challenges is not regarded as a responsibility of the employing organisation. Consequently, work-life balance is a rare consideration of managers within Chinese firms and has not been considered for formalisation within SOEs (Xiao \& Cooke) who employ around $30 \%$ of China's urban workforce (Lee, 2009; The World Bank, 2013). For women employees in particular, this creates an extra layer of tension in regard to home responsibilities and childcare arrangements, and employees invariably make their own arrangements if they wish to advance their career, often at considerable emotional cost to themselves and their families (see also, Aaltio \& Huang, 2007). According to Xiao and Cooke, women employed in SOEs are unlikely to surrender their position in response to changing personal circumstances, because of the sought-after nature of their employment. Therefore the most commonly used personal response is to out-source family responsibilities by enlisting the assistance of parents or parents-in-law, hiring domestic helpers for home responsibilities and tutors to help with children's homework (Aaltio \& Huang, 2007; Xiao \& Cooke, 2012).

\section{ARE ATTITUDES IN CHINA CHANGING?}

In spite of seeming intransigence of Chinese management mentality in regard to worklife-conflict issues faced by employees, it could well be that future adjustments will become an inevitable organisational employee retention strategy. As mentioned in the previous section, China is now witnessing the emerging influence of a new cohort of workers born between 1980 and 1989. According to Gu, Wang, Sun, and Xu (2010, p. 74), this “post-80” cohort differs in sharp and substantial ways from its counterparts in Western society (Generation Y), and also from previous generations in China. This was the first generation to be born under China's one-child-per-family policy. The upbringing and education of members of this cohort coincides with three decades of economic growth where parents and grandparents worked hard to improve prospects for them. Consequently the post-80 cohort of Chinese workers is better educated (literacy rate of 91\%), more technologically and information savvy, more aware of the world beyond China, and more ambitious than previous generations (Gu et al., 2010; Stanat, 2006). Currently this generation accounts for nearly 50\% of China's skilled workforce (Gu et al.), and its members are far more likely to actively 
manage their own careers (Hole et al., 2010) than previous generations of Chinese workers. In the next few decades this group will assume considerable influence in the future direction of a country predicted to become the next world superpower (Stanat).

The one-child-per-family planning policy also augurs a "premature era of aging" (Nielson \& Fang, 2007, p. 232) where current levels of available labour are unsustainable in terms of exponential industrial growth. The policy abruptly halted China's then burgeoning population growth from 5.4 per family in 1971 to its present rate of 1.75 . Nielson and Fang have predicted an inevitable and unavoidable gap between labour supply and demand within the next few decades in China that far outstrips similar observations in Western society where reductions in family size have not been nearly so dramatic. With labour set to become a premium workplace resource, it is therefore observed that retaining talented workers will soon become a very important consideration within Chinese organisations in order to prevent turnover (Sun, \& Wang, 2011). Sun and Pan's (2008) finding that the link between human resource practices and emotional exhaustion was particularly strong for older employees further embellishes this point, as it pinpoints an area in which organisations must focus attention in order to sustain any hope of competitive advantage and productivity gains.

According to Stanat (2006), Chinese youth are also heavily influenced by the collectivist values of their parents' generation in spite of an upbringing characterised by indulgence. Children of the post-80 generation have been raised with a sense of obligation to their family to work hard, "attend a prestigious university make a handsome salary" (Stanat, p. 91) which instills pressure to be ambitious, driven and competitive. The manifestation of such pressures results in behaviour (while seemingly similar to behaviour among ambitious young Western employees), that takes on a more determined character within Chinese workplaces (Hole et al., 2010). Hole et al. therefore warned global organisations with the intention of sustaining branches in China and Hong Kong that it is important to focus on understanding the priorities and needs of their employees in order to prevent employee turnover.

Another spin-off from China's one-child-per-family policy is a dramatic change in the role of women in society. Traditionally women have held an inferior status to men with their roles and responsibilities deemed to centre on the family (Granrose, 2007). This previous inferior status is rapidly undergoing change. Most Chinese girls currently receive a good education (Gu et al., 2010) and many are pressured to attain a position of high employment 
status (Aaltio \& Huang, 2007). According to Aaltio and Huang, women account for $47 \%$ of the total Chinese workforce. Many of these women assume a double burden because they are expected to be successful at both their career and in the home. Career expectations often include long hours and overtime, thereby contributing to the proliferation of domestic assistance for household tasks and input from workers' parents in the raising of their grandchildren. Xiao and Cooke (2012) also made the observation that many single career women choose to remain single as the long work hours divert their priorities from non-worklife considerations such as finding a partner and having children. Aaltio and Huang saw work-life conflict as one of the major barriers to women's career development, especially within the information technology (IT) industry. Granrose (2007) observed that Chinese career women have equivalent career goals to men and are motivated to work hard and achieve. Such workers are highly desirable employees. Sun and Wang (2011) cautioned organisations in regard to an increasing tendency of commercial and multi-national companies to actively and aggressively seek to recruit talented workers by poaching them from their existing employment. The increasingly competitive nature of industry in China, therefore, suggests that from an organisational standpoint, effective redress of impediments to employee retention is an imperative.

\section{THE ROLE OF MODERN TECHNOLOGY IN STRETCHING WORK-LIFE BOUNDARIES}

While information communication technology (ICT) has facilitated people's interactions in both the business and personal spheres, they have also irrevocably penetrated some formerly distinct boundaries between work and personal life. Internet capable wireless portable devices such as tablets and smartphones are proliferating exponentially within Western and Chinese societies (Berkowsky, 2013; Wang \& $\mathrm{Li}, 2012$ ). According to the International Telecommunications Union (ITU, 2013), in 2012 82.3\% of Australians used the internet, compared to $42.3 \%$ in China. However, China is rapidly expanding its telecommunications network with the rapid roll-out of a more efficient broadband infrastructure linking Chinese cities and services to Hong Kong that are state-of-the-art (ITU). Wang and Li estimated the proliferation of personal ICTs such as smartphones within Chinese cities, to be increasing by $27.24 \%$ per year. The global advent of personal smartphone technology enables the instant availability of individuals by means of phone calls, text messages and emails wherever they happen to be (Ramsay, Hair, \& Renaud, 2008). While 
this provides flexibility and instant connectivity in all spheres of life, it does have potential implications in relation to negative spillover between work and home (Berkowsky), and puts an onus on individual employees to assert some sort of control of both work-to-life (Fear, 2011; Osterlund \& Robson, 2009) and personal life-to-work (Leung, 2011; Rose, 2013) intrusions.

In regard to work-to-life influence, emails, while providing organisations with the convenience of an instant form of communication, have the capacity to extend the influence of work-life beyond any previous boundaries into employee's home time (Fear, 2011; O'Driscoll, Brough, Timms, \& Sawang, 2010; Osterlund \& Robson, 2009). This access can be afforded via company provided ICTs and/or broadband connection (Fear, 2011) or more increasingly by privately owned smartphone and personal subscriptions to broadband (Derks \& Bakker, 2014). Fear found that $24 \%$ of his respondents were provided with a company ICT device (smartphone or laptop computer) that allowed them to work outside the workplace. Of these respondents, 83\% reported that the connectivity afforded by their device intruded on their non-work time. As a new generation born since 1980 (having grown up with ICT) moves into the workplace, it is reasonable to suspect that more personally owned mobile devices such as smartphones will also be used to access work information in home time (Derks \& Bakker, 2014; Gu et al., 2010; ITU, 2013; Stanat, 2006).

According to a recent workplace report (Moretti, Howard, Spoehr, Hordacre, \& Barnett, 2013), staff working for an Australian finance corporation felt their constant ICT connectivity imposed a level of coercion to perform multiple tasks at the same time, experienced interruptions to flow of their work, and encountered expectations to be accountable and work faster. Nearly two-thirds of Moretti et al.'s respondents reported that they checked work emails and work files in their personal time. These Australian findings have resonance with the US findings of Berkowsky (2013) and the Hong Kong findings of Leung (2011). Both Leung and Moretti et al. suggested that individual control over the boundary permeation constituted the best solution to this problem. However organisational expectations that because people are online, they are therefore available for work consultation (O'Driscoll et al., 2010) may well constitute additional problems if people are experiencing a lack of selfefficacy or fear of retrenchment in regard to their work role. 
Fear's (2011, p. 2) report described "polluted time” as personal time that is interrupted by work pressures or demands, whereby people are prevented from enjoying or otherwise making the most of their time away from work. He suggested that employer access of employees' non-work time constitutes a "form of soft control over workers and a new frontier in unpaid overtime." While this may ostensibly provide a 'win' for employers, it bodes poorly for ongoing optimum performance from employees. Sonnentag and Bayer (2005, p. 393) found that employee's inability to "switch off mentally" from work was detrimental to their ability to recover from fatigue and achieve recovery to face the weight of further work (see also, von Thiele Schwarz, 2011). According to Zijlstra and Sonnentag (2006) recovery is essential physiological (as a return to baseline from a state of arousal), and psychological (as a feeling that one is capable to continue with current demands or to meet new challenges). Zijlstra and Sonnetag further warned there is no doubt that unregulated telework undertaken in non-work time affects the daily work-rest cycle and prevents people from achieving any psychological distance between work and themselves. Consequently, it is impossible to unwind and achieve psychological recovery. Rumination on work issues associated with such practices also has the capacity to negatively overrun and influence sleep quality, which in turn contributes to a deteriorating quality of work and the onset of burnout (Sonnentag \& Zijlstra, 2006).

While See and Lasikiewicz (2013) supported previously mentioned concerns about fatigue generated by work-related rumination via smartphones in non-work time, they also suggested another side of the issue: that access of non-work related input via ICTs during work time may potentially provide a counter-balancing influence. See and Lasikiewicz suggested the versatility afforded by smart phone technology has the capacity to promote recovery during stressful periods at work, by providing diversions such as music and recreational games. However, Rose (2013) highlighted an issue neglected by See and Lasikiewicz, namely that impression management is an important work-place norm and employees' recreational use of ICTs at work would not be highly regarded by superiors and/or colleagues. The boundary separating work and non-work is strongly regulated within a workplace environment via organisational cultures that do not tolerate overt recreational use of ICTs, thereby relegating such use to the urgent and surreptitious (see also, Wajcman, Rose, Bittman, \& Brown, 2010). Therefore we suggest that it is unlikely See and Lasikiewicz's suggestion of reciprocal counterbalancing between domains could be genuinely considered as 
a reasonable response to the serious problem of employee fatigue and inability to achieve detachment and recovery from work stress. It is also noted that this observation is incongruent with the increasingly common practise of organisational access of employees during their non-work time by means of work emails as previously described by Fear (2011), Leung (2011) and Berkowsky (2013).

\section{CONCLUSION}

One important insight gained within our research involving participants in Australia, New Zealand, China and Hong Kong is that the subjective nature of the work-life balance construct renders it subject to local themes in regard to acceptable work practises and workers' expectations. It is noted, however, that contemporary organisational attitudes in China may not be sustainable in the long-term, due to the changing role of women (Aaltio \& Huang, 2007; Gu et al., 2010; Xiao \& Cooke, 2012) and the advent of a new generation of workers with very different characteristics to those of their parents' generation (Gu et al., 2010; Hole et al., 2010; Stanat, 2006). Our research has identified regional differences in regard to people's perception of satisfaction with their work. However, it has also highlighted similar trends in regard to relationships between the psychosocial work environment and a sense of job satisfaction between Chinese and Western participants. This suggests that parallel processes may well be at work. We also suggest that, in view of the increasingly well-educated Chinese work-force and the proliferation of ICT connectivity, it is inevitable that workers' expectations of their workplace will inevitably undergo rapid social transition. Workers in China will rapidly learn to recognise signs of exploitation and balance these against their growing awareness of the value of their labour.

The final theme of this chapter provides a salient warning for organisations in all regions. Workplaces in all regions are adjusting to a new wave of ICT connectivity with the advent and proliferation of smartphones that provide widespread accessibility of any employee. In addition, a new generation has entered the global workforce. This cohort has grown up using ICT, and demonstrates a level of fluency and expectations of immediate access to information that exceeds any previous generation of workers. For organisations there are two important implications. Firstly, organisations will need to cultivate transparent workplace cultures that convey an appreciation of workers' worth in order to retain their services (Hole et al., 2010). 
This includes ensuring that workers are able to address important personal and work priorities in a way that alleviates tension between them (Aaltio \& Huang, 2007; Sun \& Wang, 2011). Secondly, it is important that both workers and organisations become aware of possible threats to mental health posed by constant connectivity to one's place of work. At present this is a nebulous area, with some researchers suggesting that control of such intrusion is a matter of personal agency (Leung, 2011; Moretti et al., 2013). However the threat of "polluted time" (Fear, 2011, p.2) has implications for the ongoing organisational productivity gains, in that workers are thereby diverted from any prospect of recovery from workplace strain (Sonnentag \& Bayer, 2005), and consequently their optimal performance is compromised. We suggest this is a vital concern for organisations in all regions and an important topic for future research. 


\section{REFERENCES}

Aaltio, I., \& Huang, J. (2007). Women managers' careers in information technology in China: High flyers with emotional costs? Journal of Organizational Change, 20, 227-244. doi: 10.1108/09534810710724775

Berkowsky, R. W. (2013). When you just cannot get away. Information, Communication and Society, 16, 519541. doi: 10.1080/1369118X.2013.772650

Boyar, S. L., Carr, J. C., Mosley, D. C., \& Carson, C. M. (2007). The development and validation of scores on perceived work and family demand scales. Educational and Psychological Measurement, 67, 100-115. doi: $10.1177 / 0013164406288173$

Brough, P., Dollard, M., \& Tuckey, M. (2014). Psychosocial factors at work in the Asia Pacific: Final thoughts and future research directions. In M. Dollard, A. Shimazu, R. Bin Nordin, P. Brough \& M. Tuckey (Eds.), Psychosocial factors at work in the Asia Pacific region. Melbourne, AU: Springer.

Brough, P., \& Frame, R. (2004). Predicting police job satisfaction, work well-being and turnover intentions: The role of social support and police organisational variables. New Zealand Journal of Psychology, 33(1), 8-16.

Brough, P., O'Driscoll, M., \& Kalliath, T. (2005). Confirmatory factor analysis of the Cybernetic Coping Scale. Journal of Occupational and Organisational Psychology, 78, 53-61. doi: 10.1348/096317904X23754

Brough, P., O’Driscoll, M., Kalliath, T., Cooper, C. L., \& Poelmans, S. (2009). Workplace psychological health: Current research and practice. Cheltenham, UK: Edward Elgar.

Brough, P., Timms, C., O’Driscoll, M., Kalliath, T., Siu, O. L., Sit, C., \& Lo, D. (2014). Work-life balance: A longitudinal evaluation of a new measure across Australia and New Zealand workers. International Journal of Human Resource Management, 25(19), 2724-2744. doi: 10.1080/09585192.2014.899262

Brough, P., Timms, C., Siu, O. L., Kalliath, T., O’Driscoll, M., Sit, C., ... \& Lu, C. Q. (2013). Validation of the job demands-resources model in cross-national samples: Cross-sectional and longitudinal predictions of psychological strain and work engagement. Human Relations, 66, 1311-1335. doi: $10.1177 / 0018726712472915$

Carlson, D. S., Kacmar, K., \& Williams, L. (2000). Construction and initial validation of a multidemensional measure of work/family conflict. Journal of Vocational Behavior, 56, 249-276. doi: 10.1006/jvbe.1999.1713

Chen, W. Q., Siu, O. L., Lu, J. F., Cooper, C. L., \& Phillips, D. R. (2009). Work stress and depression: The direct and moderating effects of informal social support and coping. Stress and Health, 25, 431-443. doi: $10.1002 /$ smi.1263

Clarke, S., Lee, C. H., \& Li, Q. (2004). Collective consultation and industrial relations in China. British Journal of Industrial Relations, 42, 235-254. doi: 10.1111/j.1467-8543.2004.00313.x

Cooke, F. L. (2008). The changing dynamics of employment relations in China: An evaluation of the rising level of labour disputes. Journal of Industrial Relations, 50, 111-138. doi: 10.1177/0022185607085697

Derks, D., \& Bakker, A. (2014). Smartphone use, work-home interference, and burnout: A diary study on the role of recovery. Applied Psychology: An International Review,63(3),411-440. doi: 10.1111/j.14640597.2012.00530.x 
Edwards, J., \& Rothbard, N. (1999). Work and family stress and well-being: An examination of personenvironment fit in the work and family domains. Organizational Behavior and Human Decision Processes, 77, 85-129. doi: 10.1006/obhd.1998.2813

Fear, J. (2011). Polluted time: Blurring the boundaries between work and life (Policy Brief no. 32). Canberra, Australia: The Australia Institute.

Frenkel, S. J. (2001). Globalization, athletic footwear commodity chains and employment relations in China. Organization Studies, 22, 531-562. doi: 10.1177/0170840601224001

Frenkel, S. J., \& Peetz, D. (1998). Globalization and industrial relations in East Asia: A three-country comparison. Industrial Relations, 37, 282-310. doi: 10.1111/0019-8676.00089

Granrose, C. (2007). Gender differences in career perceptions in the People's Republic of China. Career Development International, 12, 9-27. doi: 10.1108/13620430710724802

Greenhaus, J., \& Beutell, N. (1985). Sources of conflict between work and family roles. Academy of Management Review, 10, 76-88. doi: 10.2307/258214

Gu, Q., Wang, L., Sun, J. Y., \& Xu, Y. (2010). Understanding China's post-80 employees' work attitudes: An explorative study. Journal of Chinese Human Resource Management, 1, 74-94. doi: 10.1108/20408001011117635

Harzing, A., Brown, M., Koster, K., \& Zhao, S. (2012). Response style differences in cross-national research: Dispositional and situational determinants. Management International Review, 52, 341-363. doi: 10.1007/s11575-011-0111-2

Hole, D., Zhong, L., \& Schwartz, J. (2010). Talking about whose generation? Why Western generational models can't account for a global workforce. Deloitte Review, 18, 84-97. Retrieved from http://www.deloitte.com/view/en_US/us/Services/additional-services/talent-human-capitalhr/5d6e2bb18ef26210VgnVCM100000ba42f00aRCRD.htm\#

Hong, Y., Morris, M., Chiu, C, Benet-Martinez, V. (2000). Multicultural minds: A dynamic constructivist approach to culture and cognition. American Psychologist, 55, 709-720.

ITU. (2013). Measuring the information society: 2013. Geneva, Switzerland: International Telecommunications Union (ITU).

Jiang, B., Baker, R. C., \& Frazier, G. V. (2009). An analysis of job dissatisfaction and turnover to reduce global supply chain risk: Evidence from China. Journal of Operations Management, 27, 169-184. doi: 10.1016/j.jom.2007.09.002

Kalliath, T., \& Brough, P. (2008). Achieving work-life balance. Journal of Management and Organization, 143 , 224-226. doi: 10.5172/jmo.837.14.3.224

Kalliath, T., O'Driscoll, M., \& Brough, P. (2004). Confirmatory factor analysis of the General Health Questionnaire-12. Stress and Health, 20, 11-20. doi: 10.1002/smi.993

Lapierre, L. M., Spector, P. E., Allen, T. D., Poelmans, S., Cooper, C. L., O’Driscoll, M. P., ... Kinnunen, U. (2008). Family-supportive organization perceptions, multiple dimensions of work-family conflict, and employee satisfaction: A test of model across five samples. Journal of Vocational Behaviour, 73, 92106. doi: 10.1016/j.jvb.2008.02.001

Lee, J. (2009). State owned enterprises in China: Reviewing the evidence (Occasional Paper for the OECD working group on privatisation and corporate governance of state owned assets). Paris, France: Organisation for Economic Co-operation and Development (OECD). 
Leung, L. (2011). Effects of ICT connectedness, permeability, flexibility, and negative spillovers on burnout and job and family satisfaction. Human Technology, 7(3), 250-267.

Lin, J. Y. (2012). Demystifying the Chinese economy. Cambridge, UK: Cambridge University Press.

Liu, J., Siu, O., \& Shi, K. (2010). Transformational leadership and employee well-being: The mediating role of trust in the leader and self-efficacy. Applied Psychology, An International Review, 59(3), 454-479. doi: 10.1111/j.1464-0597.2009.00407.x

Lu, L., Siu, O., \& Lu, C. (2010). Does loyalty protect Chinese workers from stress? The role of affective organizational commitment in the greater China region. Stress and Health, 26, 161-168. doi: 10.1002/smi.1286

Moretti, C., Howard, S., Spoehr, J., Hordacre, A., \& Barnett, K. (2013). Work and technology over the lifecycle (Final report). Adelaide, Australia: Australian Workplace Innovation and Social Research Centre (WISeR).

Morris, M. W., Podolny, J., \& Sullivan, B. N. (2008). Culture and coworker relations: Interpersonal patterns in American, Chinese, German, and Spanish divisions of a global retail bank. Organization Science, 19, 517-532. doi: 10.1287/orsc.1070.0333

Morrison, W. M. (2013). China's economic rise: History, trends, challenges, and implications for the United States (CRS Report for Congress). Washington, DC: Congressional Research Service.

Nielson, I., \& Fang, C. (2007). Demographic shift and projected labour shortage in China. Economic Papers, 26, 231-248. doi: 10.1111/j.1759-3441.2007.tb00432.x

Noor, N. M. (2004). Work-family conflict, work- and family-role salience, and women's well-being. Journal of Social Psychology, 144, 389-405. doi: 10.3200/SOCP.144.4.389-406

O'Driscoll, M., Brough, P., Timms, C., \& Sawang, S. (2010). Engagement with information and communication technology and psychological well-being. In P. L. Perrewé \& D. C. Ganster (Eds.), New developments in theoretical and conceptual approaches to job stress (Vol. 8, pp. 269-316). Bingley, UK:Emerald Group Publishing. doi: 10.1108/S1479-3555(2010)0000008010

O'Driscoll, M. P., Brough, P., \& Kalliath, T. (2004). Work-family conflict, psychological well-being, satisfaction and social support: A longitudinal study in New Zealand. Equal Opportunities International, 23, 36-56. doi: 10.1108/02610150410787846

Osterlund, K., \& Robson, K. (2009). The impact of ICT on work-life experiences among university teaching assistants. Computers and Education, 52, 432-437. doi: 10.1016/j.compedu.2008.09.007

Peng, X. (2011). China's demographic history and future challenges. Science, 333, 581-587. doi: 10.1126/science.1209396

Ramsay, J., Hair, M., \& Renaud, K. V. (2008). Ubiquitous connectivity and work-related stress. In P. Zemliansky \& K. St Amant (Eds.), Handbook of research on virtual workplaces and the new nature of business practices (pp. 167-182). Hershey, PA: Idea Group Inc.

Richman, A., Civian, J., Shannon, L. L., Hill, J., \& Brennan, R. (2008). The relationship of perceived flexibility, supportive work-life policies, and use of formal flexible arrangements and occasional flexibility to employee engagement and expected retention. Community, Work and Family, 11, 183-197. doi: $10.1080 / 13668800802050350$

Rose, E. (2013). Access denied: employee control of personal communications at work. Work, Employment \& Society, 27, 694-710. doi: 10.1177/0950017012460329 
Seashore, S., Lawler, E., Mirvis, P., \& Cammann, C. (1982). Observing and measuring organizational change: A guide to field practice. New York, NY: Wiley.

See, A. A. Q., \& Lasikiewicz, N. (2013, July). Smartphone use and work related wellbeing. Paper presented at the International Conference on Managing the Asian Century, Singapore.

Sonnentag, S., \& Bayer, U. V. (2005). Switching off mentally: Predictors and consequences of psychological detachment from work during off-job time. Journal of Occupational Health Psychology, 10, 393-414. doi: 10.1037/1076-8998.10.4.393

Sonnentag, S., \& Zijlstra, F. R. H. (2006). Job characteristics and off-job activities as predictors of need for recovery, well-being and fatigue. Journal of Applied Psychology, 91, 330-350. doi: 10.1037/00219010.91.2.330

Spector, P. E., Allen, T. D., Poelmans, S., Lapierre, L. M., Cooper, C. L., O’Driscoll, M., ... Widerszal-Bazyl, M. (2007). Cross-national differences in relationships of work demands, job satisfaction and turnover intentions with work-family conflict. Personnel Psychology, 60, 805-835. doi: 10.1111/j.17446570.2007.00092.x

Stanat, M. (2006). China's Generation Y: Understanding the future leaders of the world's next superpower. Paramus, NJ: Homa \& Sekey.

Sun, J. Y., \& Wang, G. (2011). Integrating disparate literatures on voluntary career transition and voluntary turnover. Journal of Chinese Resource Management, 2, 23-42. doi: 10.1108/20408001111148711

Sun, L., \& Pan, W. (2008). HR practices perceptions, emotional exhaustion, and work outcomes: A conservation of resources theory in the Chinese context. Human Resource Development Quarterly, 14, 55-73. doi: 10.1002/hrdq.1225

The World Bank. (2013). China 2030: Building a modern, harmonious and creative society. Washington, DC: The World Bank (WB).

von Thiele Schwarz, U. (2011). Inability to withdraw from work as related to poor next-day recovery and fatigue among women. Applied Psychology, An International Review, 60, 377-396. doi: 10.1111/j.1464-0597.2011.00440.x

Voydanoff, P. (2005). The differential salience of family and community demands and resources for family-towork conflict and facilitation. Journal of Family and Economic Issues, 26, 395-417. doi: 10.1007/s10834-005-5904-7

Wajcman, J., Rose, E., Bittman, M., \& Brown, J. (2010). Enacting virtual connections between work and home. Journal of Sociology, 46, 257-275. doi: 10.1177/1440783310365583

Wang, H., Pan, L., \& Heerink, N. (2013). Working conditions and job satisfaction of China's new generation of migrant workers: Evidence from an inland city (Discussion Paper No. 7405). Bonn, Germany: Institute for the Study of Labor (IZA), University of Bonn.

Wang, Q., \& Li, M. (2012). Home computer ownership and Internet use in China: Trends, disparities, socioeconomic impacts, and policy implications. First Monday, 17, 1-10. doi: 10.5210/fm.v17i2.3767

Xiao, Y., \& Cooke, F. L. (2012). Work-life balance in Chinal? Social policy, employer strategy and individual coping mechanisms. Asia Pacific Journal of Human Resources, 50, 6-22. doi: 10.1111/j.17447941.2011.00005.x 
Zhang, Y., Hannum, E., \& Wang, M. (2008). Gender-based employment and income differences in urban China: Considering the contributions of marriage and parenthood. Social Forces, 86, 1529-1560. doi: 10.1353/sof.0.0035

Zijlstra, F. R. H., \& Sonnentag, S. (2006). After work is done: Psychological perspectives on recovery from work. European Journal of Work and Organisational Psychology, 15, 129-136. doi: 10.1080/13594320500513855 
Table 1 Confirmatory Factor Analysis of the Work-Life Balance Measure

\begin{tabular}{lccccccccccccc}
\hline Data samples & $n$ & $\chi^{2}$ & $d f$ & $\chi^{2} / d f$ & SRMR & GFI & TLI & CFI & PCFI & RMSEA & Mean & SD & Alpha \\
\hline Australia 1 & 5,094 & $81.14^{* * *}$ & 2 & 40.57 & .01 & .99 & .98 & .99 & .33 & .07 & 3.35 & 2.46 & .93 \\
Australia 2 & 704 & $8.32^{* * *}$ & 2 & 4.16 & .01 & .99 & .99 & .99 & .33 & .02 & 2.58 & 2.30 & .94 \\
Australia 3 & 467 & $14.31^{* * *}$ & 2 & 7.16 & .01 & .99 & .98 & .99 & .33 & .06 & 3.39 & 2.15 & .94 \\
New Zealand & 718 & $21.23^{* * *}$ & 2 & 10.61 & .03 & .99 & .97 & .99 & .33 & .07 & 3.51 & 2.74 & .84 \\
China & 3,871 & $29.23^{* * *}$ & 2 & 14.61 & .02 & .99 & .98 & .99 & .33 & .04 & 3.03 & 2.45 & .75 \\
Hong Kong & 567 & $3.18^{* * *}$ & 2 & 1.59 & .01 & .99 & .99 & .99 & .33 & .03 & 3.36 & 1.56 & .80 \\
\hline
\end{tabular}

Note. ${ }^{* * *} p<.001$. 
Table 2 Longitudinal SEM Goodness-of-Fit Statistics

\begin{tabular}{lcccccccrrr}
\hline Sample & $n$ & $\chi^{2}$ & $d f$ & $\chi^{2} / d f$ & GFI & TLI & CFI & PCFI & SRMR & RMSEA \\
\hline 1. Australia 1 & 823 & 3309.27 & 793 & 4.17 & .83 & .89 & .90 & .83 & .16 & .06 \\
2. China & 786 & 2188.75 & 793 & 2.76 & .88 & .86 & .87 & .80 & .09 & .04 \\
\hline
\end{tabular}


Figure 1. CFA Standardised Estimates of the Work-Life Balance Measure

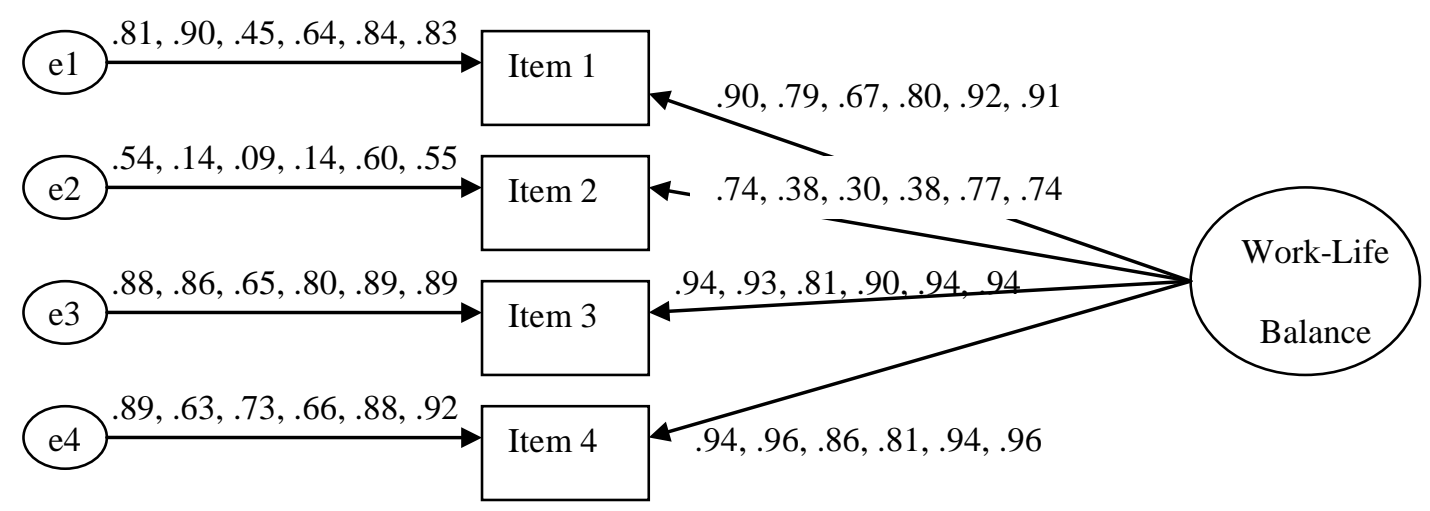

Note. Values to the left of the observed variables represent squared multiple correlations $\left(R^{2}\right)$. Values to the right of the observed variables represent standardised factor loadings $(\beta)$. Six sample results presented in order: Australia $1(n=5,094)$, New Zealand $(n=718)$, China $(n=$ 3,871), Hong Kong $(n=567)$, Australia $2(n=704)$, and Australia $3(n=467)$. 
Figure 2. Longitudinal SEM of Work-Life Balance.

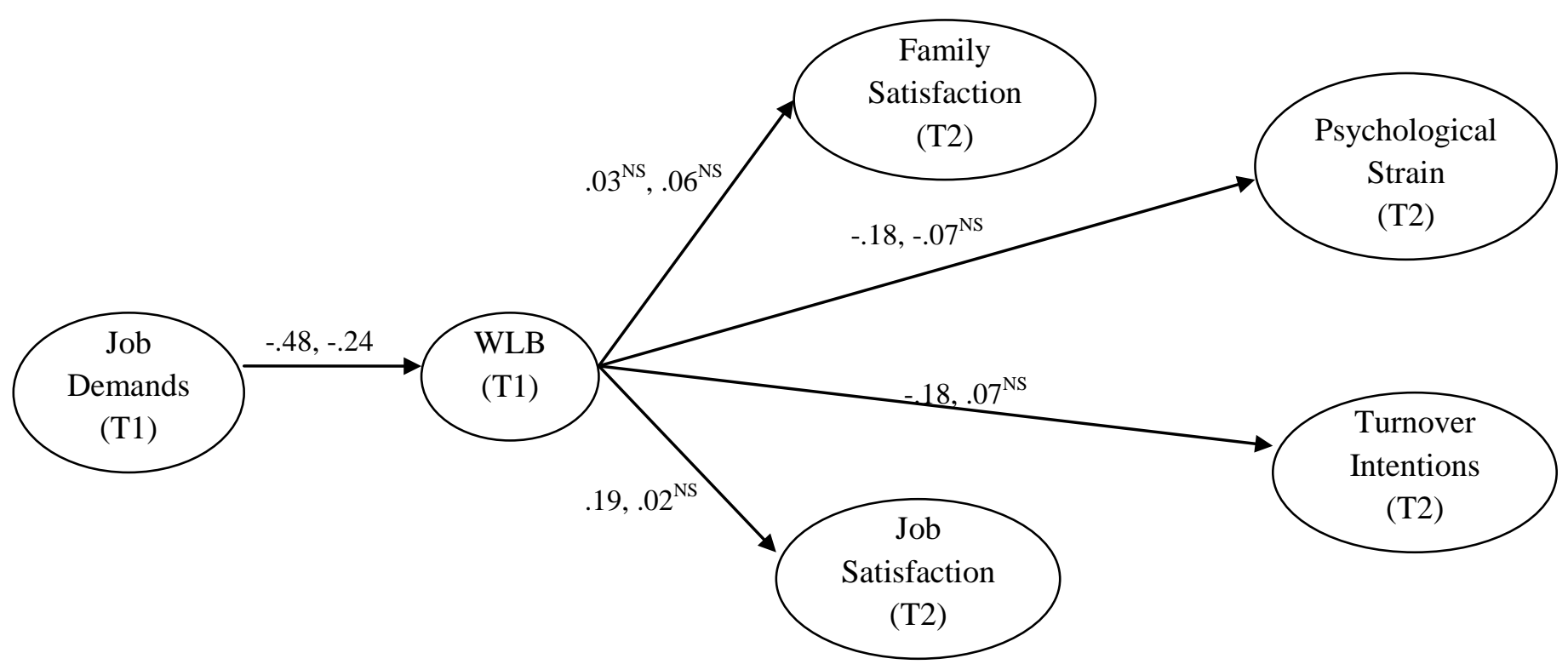

Note. Values represent standardised regression weights. Two matched samples over time results presented in order: Australia 1 ( $n=823$ ) and China $(n=786)$. All loadings significant at $p<.001$, except for ${ }^{\mathrm{NS}}=$ non-significant. WLB $=$ Work-Life Balance. T1 $=$ Time 1 , T2 $=$ Time 2 . 